\title{
A REPRESENTAÇÃO DA PAISAGEM CULTURAL SONORA DO AMBIENTE CONSTRUÍDO PELA PESSOA SURDA: PROSPECÇÕES.
}

\section{THE CULTURAL SOUNDSCAPE OF THE ENVIRONMENT BUILT AND ITS REPRESENTATION BY DEAFS: PROSPECTIONS.}

\author{
Juliana Simili de Oliveira ${ }^{1}$, M.Sc. \\ Andréa Queiroz Rêgo ${ }^{2}$, D.Sc. \\ (1) Universidade Federal do Rio de Janeiro \\ e-mail: julianasimili@gmail.com \\ (2) Universidade Federal do Rio de Janeiro \\ e-mail: andrea.queiroz@ufrj.br
}

Palavras-chave: Paisagem sonora; cultura; surdos.

Este trabalho visa expor prospecções do que seria a paisagem sonora interpretada pela pessoa surda. Ainda que venha a sugerir certa incoerência, o assunto é abordado a partir da perspectiva socioantropológica da surdez e do entendimento de que os sons do ambiente construído podem ser interpretados e representados além de sua forma física e acústica, isto é, também culturalmente.

Key-words: Soundscape; culture; deaf.

This work seeks prospections of what would be the sound landscape interpreted by the deaf person. Although it may suggest some incoherence, the subject is approached from the socioanthropological perspective of deafness and the understanding that the sounds of the built environment can be interpreted and represented beyond their physical and acoustic form, that is, also culturally.

\section{Introdução}

Os ambientes construídos pelas sociedades estão em permanente transformação em função do domínio de novas tecnologias e do melhor (re)conhecimento das relações humanas que ocorrem no espaço e com o espaço ao longo das experimentações. Este (re)conhecimento só é possível quando damos "voz" às novas demandas e aos novos usuários continuamente, pois a medida que modelamos os espaços somos modelados por eles. Esta permanente interação é mediada pelo corpo, sensorialmente, interpretada e representada pela mente de forma cultural.

Este trabalho considerada a pessoa surda o "novo" usuário dos ambientes construídos, uma vez que 


\section{$16^{\circ}$ \\ ERGODESIGN USIHC CINAHPA}

potencializará a incorporação do (re)conhecimento da experiência espacial da pessoa surda, especificamente, compreendendo como identificam e representam culturalmente as paisagens sonoras presentes nos ambientes que as rodeiam, para a modelagem dos mesmos.

Embora a surdez seja discutida há anos, ainda existem questões a serem exploradas, tais como as relações estabelecidas entre o surdo, o ambiente e suas paisagens sonoras, abordagem que se diferencia daquela que estuda as relações entre o deficiente auditivo, o espaço físico e seus sons, pois descarta as questões culturais. Ainda que o assunto sugira certa incoerência, há de se compreender como os surdos se relacionam com as paisagens sonoras que os rodeiam, construindo novas representações que possam ser compartilhadas por ouvintes e surdos.

Incorporando o universo das pessoas surdas, podemos destacar a relevância da identidade e cultura surda para a construção das representações sonoras detectadas no ambiente construído, bem como das sensibilidades inerentes aos indivíduos para apreensão do meio, considerando suas seleções e filtragens de atributos espaciais.

Neste contexto, este trabalho introduz uma discussão sobre a importância de uma representação sonora construída pelos surdos capaz de contribuir para a melhoria da qualidade dos ambientes de modo universal. O presente artigo contempla parte da Tese de Doutorado de uma das autoras, ainda em desenvolvimento, que dá prosseguimento e traz ricas contribuições para a pesquisa "Paisagem Sonora, Memória e Cultura" que vem sendo desenvolvida por sua orientadora desde 2002.

A metodologia empregada é baseada na técnica de documentação indireta, em que os dados foram levantados através de revisão bibliográfica sobre os temas: surdez, identidade, cultura, representação, e paisagem sonora. Apresenta-se as reflexões preliminares e as prospecções traçadas para a pesquisa de campo a ser desenvolvida. $16^{\circ}$ Ergodesign - Congresso Internacional de Ergonomia e Usabilidade de Interfaces Humano Tecnológica: Produto, Informações Ambientes Construídos e Transporte

$16^{\circ}$ USIHC - Congresso Internacional de Ergonomia e Usabilidade de Interfaces Humano Computador

CINAHPA | 2017 - Congresso Internacional de Ambientes Hipermídia para Aprendizagem.

\section{Definindo o sujeito em questão: a pessoa surda}

Ao iniciarmos qualquer discussão que envolva o tema da surdez é necessário delimitar a abordagem aqui empregada, que define os referenciais adotados para o entendimento da relação do surdo com a sonoridade espacial.

Por muitos anos, a perspectiva predominante foi aquela decorrente de estudos clínicos-terapêuticos, cujo termo apropriado para se referir à pessoa que não escuta era (e por muitos ainda é) o "deficiente auditivo". Tal referencial remete ao final século XIX e consiste no modelo médico de interpretação da surdez. Skliar (1998, p.52) afirma que o principal objetivo desta concepção era de "fazer os surdos falarem a todo custo", por meio da oralização. Sob este ponto de vista, a expressão deficiente auditivo remete a uma classificação restritamente biológica.

Segundo Behares (2000, p.2), no discurso clínico, que toma o ouvinte como modelo, o surdo "é" fundamentalmente como o ouvinte, porém, lhe falta "algo"; portanto, nessa lógica o surdo é um ouvinte imperfeito. Fica implícita nessa perspectiva a imagem de diminuição. A interpretação unicamente clínica desconsidera outros valores que caracterizam os surdos, já que são ressaltadas as convenções ouvintes do que venha a ser a surdez. Isso nos direciona a uma outra abordagem, que visa englobar a pessoa surda como sujeito, em sua integralidade, como um ser humano completo e capaz.

Rejeitando a surdez como patologia, nas três últimas décadas, os estudos se voltam ao entendimento da surdez de modo ideológico. Assim, rejeita-se uma abordagem exclusivamente clínica-terapêutica e se aproxima de paradigmas socioculturais, a partir de uma concepção socioantropológica da surdez. Das múltiplas contribuições possíveis a essa mudança, a difusão dos modelos denominados bilíngues/biculturais e o aprofundamento das concepções sociais e antropológicas da surdez foram possivelmente as mais relevantes (SKLIAR, 1998). 


\section{$16^{\circ}$ \\ ERGODESIGN USIHC CINAHPA}

$16^{\circ}$ Ergodesign - Congresso Internacional de Ergonomia e Usabilidade de Interfaces Humano Tecnológica: Produto, Informações Ambientes Construídos e Transporte

$16^{\circ}$ USIHC - Congresso Internacional de Ergonomia e Usabilidade de Interfaces Humano Computador

CINAHPA | 2017 - Congresso Internacional de Ambientes Hipermídia para Aprendizagem.
A essência da surdez enquanto diferença abrange o entendimento de que os surdos pertencem a um grupo minoritário, linguística e culturalmente, principalmente por utilizar outra via de acesso a informações, manifestada por modalidades visuaisgestuais de línguas (OLIVEIRA, 2011; GESSER, 2009). Sob essa outra perspectiva, a experiência da surdez é reconstituída como um traço cultural, tendo a língua de sinais como elemento significante para essa definição (SÁ, 2002). O surdo passa a ser entendido por meio de seu referencial enquanto pessoa e enquanto sujeito, e não mais como alguém que é portador de uma patologia a ser tratada. Logo, o termo "deficiência" não é mais apropriado para a comunidade surda, pois ela se organiza em torno da língua de sinais, sendo denominada como "comunidade sinalizante" (OLIVEIRA, 2011). Segundo Behares (2000, p. 2), o surdo "não é diferente unicamente porque não ouve, mas porque desenvolve potencialidades psicoculturais diferentes das dos ouvintes".

Quanto a terminologia mais apropriada, Sá (2002) afirma que o termo "surdo" é aquele com o qual as pessoas que não ouvem referem-se a si mesmos e aos seus pares. Para ela, uma pessoa surda é alguém que vivencia um déficit de audição que o impede de adquirir, naturalmente, a língua oral/auditiva usada pela comunidade majoritária e que constrói sua identidade calcada principalmente nesta diferença, utilizando-se de estratégias cognitivas e de manifestações comportamentais e culturais que se diferem da maioria das pessoas que ouvem. A definição da surdez pelos surdos passa muito mais por sua identidade grupal do que por sua característica física que pretensamente os fazem 'menos' (ou 'menores') que os indivíduos ouvintes.

Tendo como referência as diferenças identitárias e de interpretação cultural que os surdos apresentam, adotamos como norteador deste trabalho, o termo "surdo" e suas apropriações enquanto grupo minoritário, com as características que lhes são próprias. É baseado nessa construção de uma identidade particular, que este trabalho acredita na riqueza de experiências que o surdo terá com o mundo que o cerca, especialmente no que tange as sonoridades existentes no ambiente experimentado.

\section{Cultura, identidade e representação: a língua de sinais.}

Partindo da compreensão da surdez pelo seu viés socioantropológico, três conceitos são fundamentais para a relação do surdo com sonoridade no ambiente construído: cultura, representação e identidade. Longe de querer definir ou findar a discussão a respeito de tais conceitos, iremos apenas delinear um parâmetro com o qual foi possível estruturar a questão proposta.

Acerca da cultura, concordamos com Geertz (2008) ao dizer que o contexto está atrelado ao significado. Para ele, o objetivo da antropologia é o alargamento do universo do discurso humano, quando ao invés de simplesmente falar, possamos conversar. "Como sistemas entrelaçados de signos interpretáveis [...] ela [a cultura] é um contexto, algo dentro do qual eles podem ser descritos de forma inteligível". Assim, "a cultura é pública porque o significado o é" (GEERTZ, 2008, p. 910). Neste sentido entendemos que a cultura envolve agentes contextuais, ativos ou não, que atuam de forma direta ou indireta através de um sistema simbólico constituído em um meio e por um grupo de pessoas as quais compartilham de entendimento e experiências semelhantes de vida.

Para Stuart Hall (2003), a "cultura é uma produção" que depende do conhecimento da tradição, a fim de nos capacitar a nos produzir a nós mesmos de novo, como novos tipos de sujeitos, através de um processo de constante mutação. Segundo ele, nós estamos em um constante processo de formação cultural, sendo a cultura não uma questão de ontologia, de ser, mas sim de tornar-se.

Portanto, o que vem a ser a cultura surda? Quadros (2004) entende "cultura surda" como sendo a identidade cultural de um grupo de surdos que se define enquanto grupo diferente de outros grupos. Mesmo se configurando em uma cultura multifacetada, apresenta características que são específicas: ela é visual e traduz-se de forma visual. Assim, tais características visuais distinguem o modo com que o surdo irá ver, sentir e se relacionar com o mundo (GESSER, 2009). 


\section{$16^{\circ}$ \\ ERGODESIGN USIHC CINAHPA}

$16^{\circ}$ Ergodesign - Congresso Internacional de Ergonomia e Usabilidade de Interfaces Humano Tecnológica: Produto, Informações Ambientes Construídos e Transporte

$16^{\circ}$ USIHC - Congresso Internacional de Ergonomia e Usabilidade de Interfaces Humano Computador

CINAHPA | 2017 - Congresso Internacional de Ambientes Hipermídia para Aprendizagem.
Perlin (2015) corrobora tais afirmações ao declarar que a cultura surda como diferença constitui-se em uma atividade criadora, através de símbolos e práticas próprios ao surdo e à sua consciência de pertencimento a um mundo de experiência, ações e atuações visuais e não auditivas.

Como em outras culturas, os surdos constituem-se um grupo heterogêneo, em transição e em constante transformação. Ainda que a cultura surda seja construída coletivamente por indivíduos diferentes, estes se encontram em suas semelhanças. E é a partir dessa semelhança, desse encontro com o outro, da alteridade, que passa a estar em voga a noção de identidade.

Perlin (2015, p. 54), pesquisadora brasileira surda, diz que o encontro surdo-surdo é fundamental para a construção da identidade surda. Segundo ela, "é como abrir o baú que guarda os adornos que faltaram ao personagem". Laborit (2000, p. 37) afirma que ao se deparar com um semelhante, passou a descobrir o mundo que a rodeia e, mais ainda, a perceber que faz parte desse mundo. A autora afirma que a partir do momento que teve contato com uma linguagem gestual estruturada, pode tornar-se um ser humano comunicante, passível de construir frases, mas também capaz de se construir.

Hall (2006) afirma ser a identidade algo formado ao longo do tempo, por meio de processos inconscientes, e não algo inato, que existe na consciência no momento do nascimento. Para ele, a identidade permanece sempre incompleta, em processo e sempre sendo formada. Neste sentido, como aponta Silva (2000), a identidade e a diferença têm de ser ativamente produzidas, e fazem parte de um mundo cultural e social. Segundo ele, somos nós que as fabricamos num contexto cultural e social.

Como em qualquer outra identidade, a identidade surda não é fixa, estática. Ao contrário, ela se forma por diferentes contextos e situações, por perspectivas diversas, de modo que os sujeitos possam ir a diferentes direções, assumindo posturas múltiplas e até mesmo contraditórias. Entretanto, apesar de sua multiplicidade, um dos fatores que caracterizam a identidade surda é o fato de que, os múltiplos significados apontam para a perspectiva de ser do surdo. Isto é, ainda que exista um sujeito surdo multifacetado que viva em posições individuais, este se constrói e é construído dentro de uma sociedade sob a força da diferença (PERLIN, 1998).

Quanto à noção de representação, Reily (2003) diz ser inevitável que algum sistema semiótico seja necessário para significar o mundo. Todavia, serão as possibilidades de acesso e contato do ser com o ambiente social que determinarão o tipo de sistema semiótico mais condizente para a constituição da linguagem e do pensamento. E este é o ponto fundamental sobre a importância da língua de sinais: a língua é imprescindível para que o surdo possa se constituir como sujeito do e no mundo (SILVA, 2003).

Segundo Hall (1997), a representação consiste no processo pelo qual os membros de uma mesma cultura produzem significados, e isso envolve o uso da linguagem, de signos e de imagens que significam ou representam as coisas.

A partir de tais referências, podemos afirmar que o que terá significado para uma pessoa inserida em um determinado contexto pode não expressar o mesmo para outra pessoa que não compartilhe dos mesmos significados estabelecidos. Deste modo, acredita-se que a relação que o sujeito ouvinte terá em um determinado ambiente seja distinta daquela estabelecida pelo sujeito surdo neste mesmo ambiente, pois irá perpassar por códigos de inteligibilidade diferentes.

\section{Paisagem sonora e surdez}

Ao pensarmos no que vem a ser o "som", há uma tendência de se considerar o seu âmbito físico e acústico, da emissão e recepção de ondas sonoras, no seu espectro audível, excluindo-se, assim, as percepções das vibrações. Ainda que o valor tangível do som possa ser relacionado à noção física e acústica das ondas sonoras, a sonoridade não se detém em tais aspectos, atingindo por meio da percepção, as sensações e evocando emoções e memórias introspectivas ao ser humano. E isso se 


\section{$16^{\circ}$ \\ ERGODESIGN USIHC CINAHPA}

dá através de associações simbólicas, construídas por suas relações sociais, culturais e identitárias.

O som pode remeter a algo positivo ou negativo, porém, sempre é tido como um dos elementos qualificadores do espaço vivido. Wisnik (1989, p. 28) diz que "o som é um objeto subjetivo, que está dentro e fora, não pode ser tocado diretamente, mas nos toca com uma enorme precisão". O som, com todas as suas variações - presenças e ausências -, influencia e altera a percepção que temos de um espaço, contribuindo para transformálo ou não em um lugar.

Embora a visão seja fundamental para a percepção espacial, os sons, os odores e as sensações térmicas, mesmo que efêmeros e dinâmicos, não podem ser menosprezados, enquanto responsáveis pela construção da ambiência dos lugares e consequentemente da construção sensível dos espaços. Os lugares são criados e experimentados como resultado de diferentes, e às vezes única, misturas de sensações em ressonância com a nossa memória individual e coletiva.

Rêgo (2006) afirma que os sons são capazes de auxiliar na orientação do espaço, na delimitação dos territórios, no relacionamento entre os seres vivos e seus processos de aprendizagem, bem como para o bem estar físico e emocional dos indivíduos.

Observamos, portanto, que a percepção dos sons não ocorre de maneira isolada, mas também através da interpretação de contextos, em uma globalidade de sons denominada de "paisagem sonora" (SCHAFER, 2001, p. 11).

Rêgo (2006) afirma que uma paisagem sonora é a extensão do território que se pode escutar, abrangendo todos os sons produzidos no ambiente, sendo também sempre uma criação cultural.

Portanto, uma paisagem sonora não se detém ao que pode ser escutado, mas ao que cada pessoa pode ouvir e compreender, em função do seu conhecimento, possibilitando um posicionamento individual em relação aos sons que serão ouvidos em uma determinada época e lugar. $16^{\circ}$ Ergodesign - Congresso Internacional de Ergonomia e Usabilidade de Interfaces Humano Tecnológica: Produto, Informações Ambientes Construídos e Transporte

$16^{\circ}$ USIHC - Congresso Internacional de Ergonomia e Usabilidade de Interfaces Humano Computador

CINAHPA | 2017 - Congresso Internacional de Ambientes Hipermídia para Aprendizagem.
Neste sentido, vemos que onde quer que o homem esteja ou a época em que ele viva sempre haverá uma situação sonora circundante e que poderá ser compreendida sob diferentes pontos de vista, com base no repertório de cada pessoa. Deste modo, os sons tendem a adquirir significados semelhantes para aquelas pessoas que dominam o mesmo código e a mesma linguagem, já que pertencem a uma mesma cultura.

Podemos afirmar, assim, que os sons podem ser experimentados também além da audição, por meio do corpo e das interpretações que fazemos quando o percebemos em nossa experiência cotidiana. Considerando o delineamento do sujeito desta pesquisa, obviamente os sons não serão reconhecidos através da escuta. Almeja-se, porém, reconhecer como os sons são percebidos pelo mundo surdo, em sua experiência visual e sensível (vibrações) acerca do som. Considerando que pessoas que dominam os mesmos códigos compartilham de uma mesma cultura e dominam uma mesma linguagem, pretende-se verificar, portanto, se a compreensão de significados e representações das paisagens sonoras é compartilhada pelos surdos.

Neste contexto, dado a ausência da experiência sonora como os ouvintes a conhecem, como a pessoa surda experimenta os sons? Uma vez que o surdo não é excluído da percepção espacial e sonora, como ele a qualifica e representa? Embora ainda não tenhamos as respostas para tais questionamentos, iremos apresentar os caminhos que estamos percorrendo nesta busca.

\section{Prospecções e considerações finais}

Realizada a exposição dos conceitos que envolvem este trabalho, apresentamos aqui a prospecção do estudo de caso, bem como as expectativas dos seus resultados.

Crendo nessa construção da paisagem sonora pelo surdo, iremos buscar como ocorrem tais construções, com base em seus contextos e percepções, traduzidas por meio da sua própria identidade e cultura, bem como das representações através da Libras - a Língua Brasileira de Sinais.
Realização:

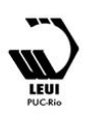




\section{$16^{\circ}$ \\ ERGODESIGN USIHC CINAHPA}

Assim, o delineamento do estudo de caso ocorre tendo como intuito averiguar como o som é experimentado pelo surdo e como é representado culturalmente após ser percebido sinestesicamente.

Para isso, o estudo de caso é proposto mediante etapas de aproximação gradativas com o universo estudado, buscando coletar dados que contribuam para uma construção do que venha a ser a "paisagem sonora além da audição". Por se tratar de um estudo que envolve seres humanos, esta pesquisa foi submetida e recentemente aprovada pelo Comitê de Ética, através da Plataforma Brasil.

Faz uma abordagem de análise interdisciplinar e qualitativa, desenvolvida em três passos metodológicos: (1) levantamento documental das palavras que representam os sons em Libras; (2) interpretação da vivência sonora dos surdos, através de uma atividade de associação de palavras e lugares; e, por fim, (3) passeio sonoro-sensível, realizado em um percurso urbano pré-definido. Esses procedimentos foram construídos pelas pesquisadoras, tendo como referencia as metodologias já existentes "passeios sonoros" (TRUAX, 2001) e "método dos percursos comentados" (THIBAUD, 2002), sendo estas livremente adaptadas para o propósito e condições identificadas.

A partir dos dados coletados, buscar-se-á configurar uma qualificação sistematizada das representações sonoras construídas através da percepção das pessoas surdas. Neste sentido, tal análise contribuirá para a construção do que chamaremos de "paisagem sonora além da audição", uma nova forma de representação sonora, entendendo que o surdo, a seu próprio modo, explora a relação do som com o espaço, sendo sensível ao mesmo.

Com base na discussão até aqui apresentada e nas prospecções do futuro estudo de caso, podemos ter como premissa que exista sim uma representação da paisagem cultural sonora construída a partir do ambiente experienciado pela pessoa surda. Isto, pois, ainda que os surdos estejam inseridos em um mesmo ambiente que os ouvintes, eles criariam leituras espaciais distintas. Eles poderão construir $16^{\circ}$ Ergodesign - Congresso Internacional de Ergonomia e Usabilidade de Interfaces Humano Tecnológica: Produto, Informações Ambientes Construídos e Transporte

$16^{\circ}$ USIHC - Congresso Internacional de Ergonomia e Usabilidade de Interfaces Humano Computador

CINAHPA | 2017 - Congresso Internacional de Ambientes Hipermídia para Aprendizagem.

representações, também, alicerçadas no intangível / invisível, à luz da identidade e cultura surdas.

\section{BIBLIOGRAFIA}

BEHARES, L. E. Novas correntes na educação do surdo: dos enfoques clínicos aos culturais.

Cadernos de Educação Especial, Universidade

Federal de Santa Maria, p. 1-23, 2000.

GEERTZ, C. A interpretação das culturas. 1. ed. Rio de Janeiro: LTC, 2008.

GESSER, A. Libras? Que lingua é essa?: Crenças e preconceitos em torno da língua de sinais e da realidade surda. São Paulo: Parábola Editorial, 2009.

HALL, S. The work of representation. In: HALL, S. (org.) Representation: Cultural representations and signifying practices. Londres: Sage Publications, 1997. p. 15-69.

Da diáspora: Identidades e mediações culturais. Belo Horizonte: Editora UFMG; Brasília: Representação da UNESCO no Brasil, 2003.

A identidade cultural na pós-

modernidade. 11. ed. Rio de Janeir: DP\&A Editora, 2006.

LABORIT, E. O grito da gaivota. $2^{\mathrm{a}}$. ed. Lisboa: Editorial Caminho, SA, 2000.

OLIVEIRA, L. A. Fundamentos Históricos, Biológicos e Legais da Surdez. Curitiba: IESDE Brasil S.A., 2011.

PERLIN, G. Histórias de vida surda: Identidades em questão. $51 \mathrm{f}$. Dissertação (Mestrado).Universidade Federal do Rio Grande do Sul. Porto Alegre. 1998.

. Identidades surdas. In: SKLIAR, C. (org.)

A surdez: um olhar sobre as diferenças. 7. ed.

Porto Alegre: Mediação, 2015. p. 51-73.

QUADROS, R. M. O tradutor e intérprete de língua brasileira de sinais e língua portuguesa. Brasília: MEC / SEESP, 2004. 


\section{$16^{\circ}$}

ERGODESIGN USIHC CINAHPA $16^{\circ}$ Ergodesign - Congresso Internacional de Ergonomia e Usabilidade de Interfaces Humano Tecnológica: Produto, Informações Ambientes Construídos e Transporte

$16^{\circ}$ USIHC - Congresso Internacional de Ergonomia e Usabilidade de Interfaces Humano Computador

CINAHPA | 2017 - Congresso Internacional de Ambientes Hipermídia para Aprendizagem.

RÊGO, A. Q. Paisagens sonoras e identidades urbanas: os sons nas crônicas cariocas e as transformações do bairro de Copacabana (1905-1968). 298 f. Tese (Doutorado em

Urbanismo) - PROURB - Universidade Federal do Rio de Janeiro. Rio de Janeiro - RJ. 2006.

REILY, L. H. As imagens: o lúdico e o absurdo no ensino de arte para pré-escolares surdos. In:

SILVA, I. R.; KAUCHAKJE, S.; GESUELI, Z. M. (org.) Cidadania, surdez e linguagem: desafios e realidades. São Paulo: Plexus, 2003.

SÁ, N. R. L. Cultura, poder e educação de surdos. Manaus: Editora da Universidade Federal do Amazonas, 2002.

SCHAFER, R. M. A afinação do mundo. São Paulo: Editora da UNESP, 2001.

SILVA, A. B. P. Surdez, inteligência e afetividade. In: SILVA, I. R.; KAUCHAKJE, S.; GESUELI, Z. M. (orgs.) Cidadania, surdez e linguagem: desafios e realidades. São Paulo: Plexus, 2003. p. 89-97.

SILVA, T. T. A produção social da identidade e da diferença. In: SILVA, T. T. (org.) Identidade e diferença: a perspectiva dos estudos culturais. Petrópolis, RJ: Vozes, 2000.

SKLIAR, C. Bilingüismo e biculturalismo. Revista Brasileira de Educação, São Paulo, n. 8, p. 44-57, maio-jun.-jul.-ago. 1998.

THIBAUD, J.-P. Une approche des ambiances urbaines: le parcours commenté. In: JOLÉ, M. Espaces publics et cultures urbaines. Paris: Certu, 2002. p. 257-270.

TRUAX, B. Acoustic Communication. Westport: Greenwood, 2001.

WISNIK, J. M. O som e o sentido: Uma outra história das músicas. São Paulo: Companhia das Letras, 1989. 